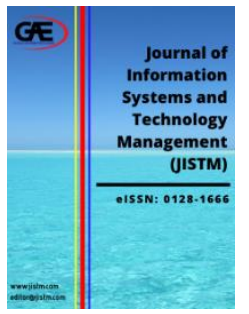

\author{
JOURNAL OF INFORMATION \\ SYSTEM AND TECHNOLOGY \\ MANAGEMENT (JISTM)

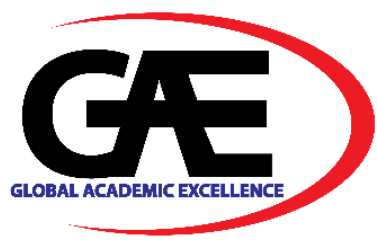

\title{
DETERMINATION AND MAPPING OF THE TERRESTRIAL GRAVITY ANOMALIES IN THE MOUNTAINOUS AREAS OF IRAQ
}

\author{
Shazad Jamal Jalal ${ }^{1,5^{*}}$, Tajul Ariffin Musa², Ami Hassan Md Din ${ }^{3}$, Wan Anom Wan Aris ${ }^{4}$ \\ 1 Faculty of Built Environment and Surveying, Universiti Teknologi Malaysia (UTM), Malaysia. \\ Email: shazad.jalal@univsul.edu.iq \\ 2 Faculty of Built Environment and Surveying, Universiti Teknologi Malaysia (UTM), Malaysia. \\ Email: tajulariffin@utm.my \\ 3 Faculty of Built Environment and Surveying, Universiti Teknologi Malaysia (UTM), Malaysia. \\ Email: amihassan@utm.my \\ 4 Faculty of Built Environment and Surveying, Universiti Teknologi Malaysia (UTM), Malaysia. \\ Email:wananom@utm.my \\ 5 College of Engineering, University of Sulaimani, Iraq. \\ * Corresponding Author
}

\section{Article Info:}

Article history:

Received date: 01.10.2021

Revised date: 01.11.2021

Accepted date: 20.11.2021

Published date: 01.12.2021

\section{To cite this document:}

Jalal, S. J., Musa, T. A., Md Din, A. H., \& Aris, W. A. W. (2021). Determination And Mapping Of The Terrestrial Gravity Anomalies In The Mountainous Areas Of Iraq. Journal of Information System and Technology Management, 6 (24), 213-225.

DOI: $10.35631 / J I S T M .624021$

This work is licensed under CC BY 4.0



Abstract:

Gravity data and computing gravity anomalies are regarded as vital for both geophysics and physical geodesy fields. The mountainous areas of Iraq are characterized by the lack of regional gravity data because gravity surveys are rarely performed in the past four decades due to the Iraq-Iran war and the internal unstable political situation of this particular region. In addition, the formal map of the available terrestrial gravity which was published by the French Database of Bureau Gravimetrique International (International Gravimetric Bureau-in English) (BGI), introduces Iraq and the study area as a remote area and in white color because of the unavailability of gravity data. However, a dense and local (not regional) gravity data is available which was conducted by geophysics researchers 13 years ago. Therefore, the regional gravity survey of 160 gravity points was performed by the authors at an average $11 \mathrm{~km}$ apart, which was covers the whole area of Sulaymaniyah Governorate (part of the mountainous areas of Iraq). In spite of Although the risk of mine fields within the study area, suitable safe routes as well as a helicopter was used for the gravity survey of several points on the top of mountains. The survey was conducted via Lacoste and Romberg geodetic gravimeter and GPS handheld. The objective of the study is to determine and map the gravity anomalies for the entire study area, the data of which would assist different geosciences applications. 
Keywords:

Gravity Survey, Gravity Anomalies, Mountainous Areas, Iraq.

\section{Introduction}

Gravity is both a vector and an acceleration quantity. The gravitational field is divided into two parts: the fundamental, which is caused by attraction and is formulated by Newton's law, and the secondary, which is caused by Earth's rotation and is around $0.33 \%$ of the first at the equator and less at other locations (Heiskanen and Meinesz, 1958).

Geophysical data, such as gravitational measurements, reveal real variations that can be mapped and used in a variety of geological and geodetic applications, such as oil and mineral exploration and geoid modeling at the local and regional scales. (Jalal et al., 2019).

The gravitational field of the Earth is used to determine heights at the surface (Vaniček et al., 2012). Furthermore, due to the Earth's ellipsoidal form, rotation, irregular relief, and internal mass distribution, the gravitational attraction varies significantly. As a result, the gravity difference between the equator and the poles is around $5 \mathrm{~cm} / \mathrm{sec} 2$ (or $5 \mathrm{Gal}$ and $1 \mathrm{Gal}=1000$ $\mathrm{mGal}$ after Galileo). The average gravity at the Earth's surface, on the other hand, is about 980 Gal. (Kearey, 2002; Shahani 1976; Heiskanen and Mortiz, 1967).

Newton's law of gravity is the theoretical foundation for the study of gravity (Kearey, 2002). Gravity measurements may be taken on the ground (terrestrial), in the air (airborne), at sea (shipborne), or on satellites (space-borne) (Pinon, 2016).

Without corrections for all variations in the Earth's gravitational field that are not attributable to changes in density under rocks, gravity measurements at observed stations cannot be used or interpreted. Gravitational reduction, or reduction to a geoid, is the method of processing gravity, with sea level being the most suitable level datum. After the gravity survey, during the analysis of the gravity data, these gravitational reductions must be adjusted for station elevation, the impact of surrounding topography, and latitude to assess gravity anomalies reflecting variations in acceleration for each measured point in the study area. (Kearey, 2002; Parasnis, 1997; Shahani, 1976; Dobrin, 1960).

Due to rare and sparse gravitational measurements, the study area and Iraq as a whole are considered as remote area. Figure 1 shows that the region under investigation is remote, and the white color indicates a lack of gravity data according to the French Database of Bureau Gravimetrique International (International Gravimetric Bureau-in English) BGI (ESA, 1999). The aim of this paper is to provide an overview of the existence of the gravity anomaly in Iraq's mountainous areas. This will be accomplished by conducting a terrestrial gravity survey in the area under the study of Sulaymaniyah Province.

\section{Study Area}

Sulaymaniyah Governorate (Province) is located in Iraq's east northern region, and it encompasses a significant portion of the Kurdistan Region's mountainous terrain. Iran shares a 300 -kilometer boundary with Sulaymaniyah Governorate. The study area is located at $38^{\circ} \mathrm{N}$ in 
Volume 6 Issue 24 (December 2021) PP. 213-225 DOI: 10.35631/JISTM.624021

the UTM district and it is bounded by latitudes of $34.7^{\circ}-36.5^{\circ} \mathrm{N}$ and longitudes of $44.5^{\circ}-46.3^{\circ}$ E. The Province occupies 17,023 km2 and accounts for $3.9 \%$ of Iraq's total land area (see Figure 2). (Ministry of Planning, 1992).

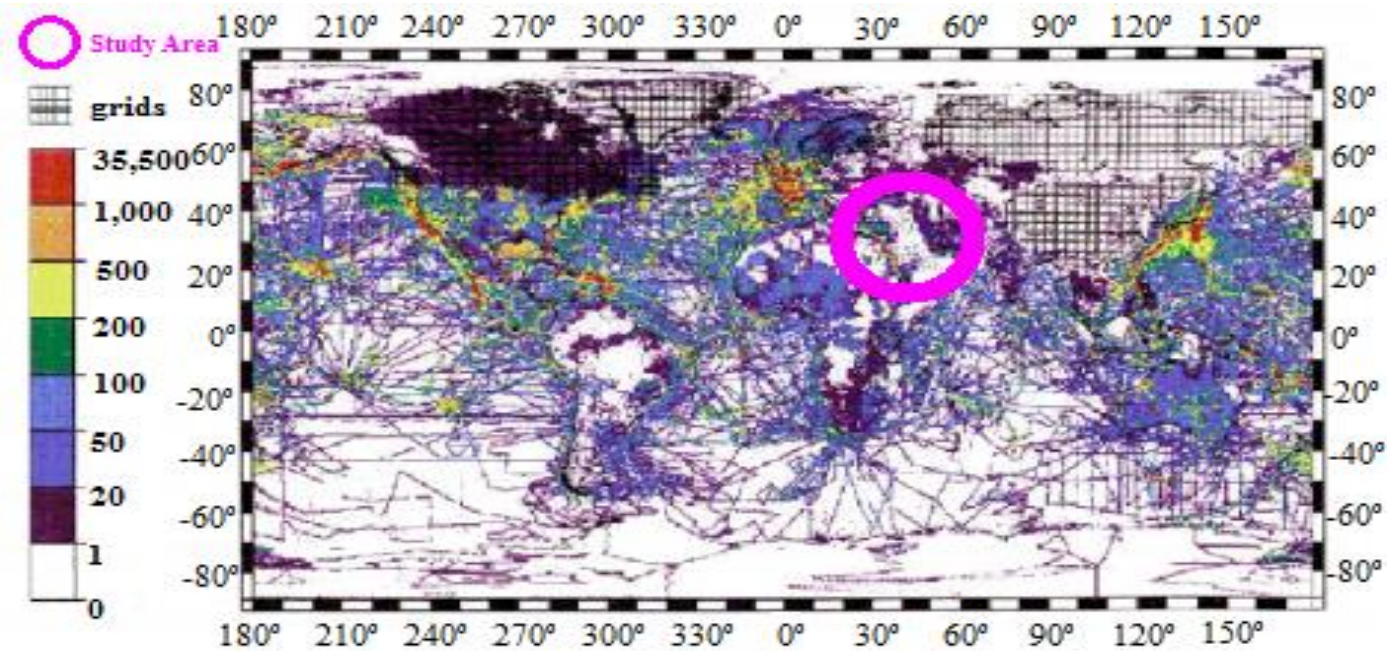

Figure 1: Empty Gravity Information of Iraq Presented in a White Color by the BGI Global Gravity Map

Source: (ESA, 1999).

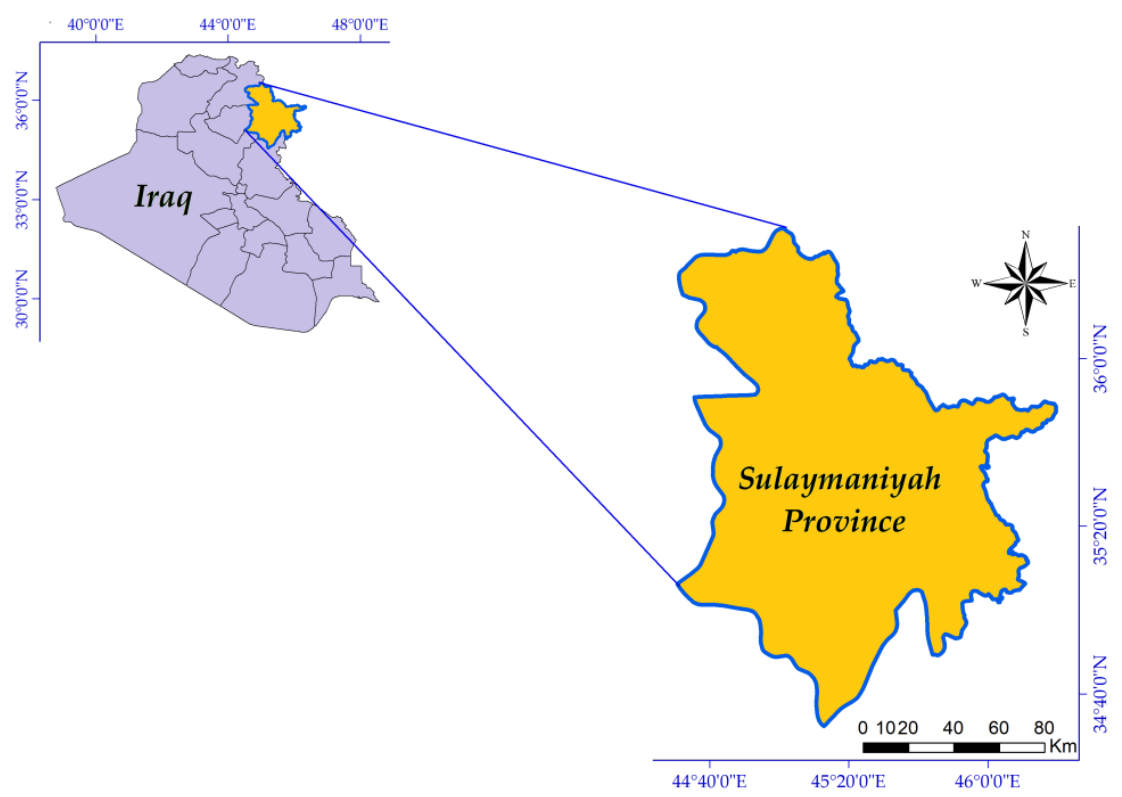

Figure 2: Location of the Study Area

\section{Constraints of Performing the Gravity Survey}

Different factors, such as cost, lack of accessibility, and mine fields, act as constraints and restrictions in the terrestrial gravity survey in the study area. However, the Sulaymaniyah has the highest reported number of mine casualties in Iraq in 2017 (MHE, 2017). Furthermore, the 
Volume 6 Issue 24 (December 2021) PP. 213-225

DOI: 10.35631/JISTM.624021

dangerous region is situated in the mountainous areas of the Iraq-Iran border by a strip of around $50 \mathrm{~km}$ in width that was part of the war from 1980 to 1988.

\section{The Gravity Survey}

The gravity survey was conducted to obtain the gravity data at a regional scale in August 2019.

\section{Methodology}

The methodology includes both gravity survey and processing the gravity data to be ready for computing and mapping the gravity anomalies.

\section{Instrumentation}

The two main instruments used in gravity surveying are the Lacoste and Romberg geodetic gravimeter and the GPS handheld for measuring gravity and positioning survey points, respectively.

\section{Performing the Gravity Survey}

As shown in Figure 3, the gravity survey survey points Autodesk Civil 3D Software, covers the entire study area by measuring the gravity of 160 points.

Furthermore, the distance between the 2021 ranges between $5 \mathrm{~km}$ and $20 \mathrm{~km}$ as shown in Table 1. 
Volume 6 Issue 24 (December 2021) PP. 213-225

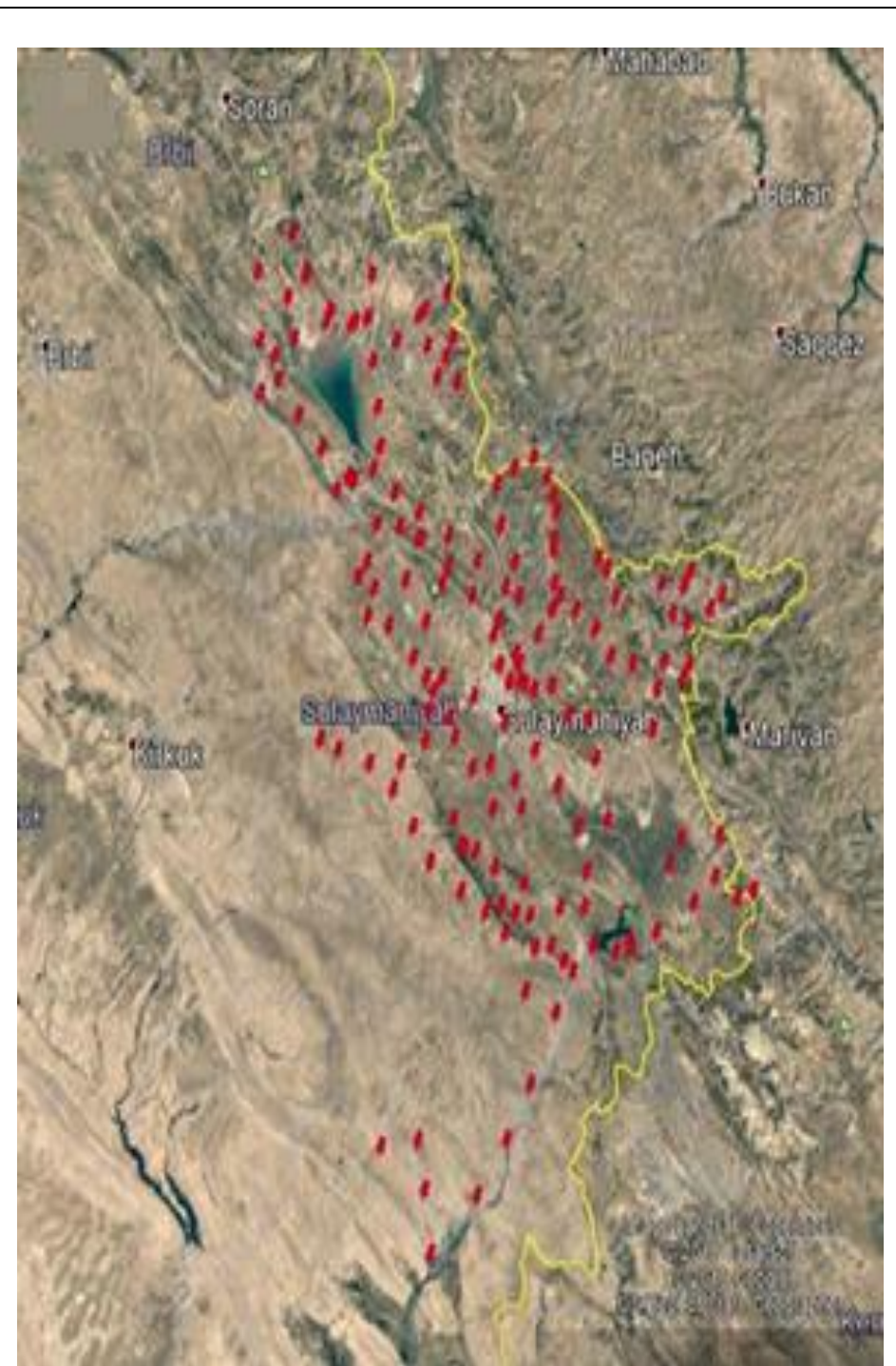

DOI: 10.35631/JISTM.624021

Figure 3: Location of the Measured Gravity Points

\begin{tabular}{cccc}
\hline \multicolumn{4}{c}{ Table 1: Distance Between the Surveyed Gravity Points in the Study Area } \\
\hline No. & Distance Interval $(\mathbf{k m})$ & No. of Lines & Percentage $\mathbf{( \% )}$ \\
\hline 1 & $<5$ & 56 & 12 \\
2 & $5-<10$ & 208 & 44 \\
3 & $10-<15$ & 115 & 25 \\
4 & $15-<20$ & 44 & 9 \\
5 & $>20$ & 47 & 10 \\
& Total & 470 & 100 \\
$*$ Average Distance Interval between the gravity points $=11.8$ Km \\
**Total number of possible triangle network between the gravity points $=305$. \\
***Total number of sides between the gravity points without repetition $=470$. \\
\hline
\end{tabular}




\section{Deriving the Orthometric Height for the Survey Points}

The GPS positioning of the elevation represents the ellipsoidal height (h) and must therefore be converted to the orthometric height $(\mathrm{H})$. For this reason, the necessary $\mathrm{H}$ for survey points as well as for processing the gravity data derived from the Digital Terrain Model (DTM) provides by the global mapper 21.0 software.

\section{The Processing of the Terrestrial Gravity Data}

The processing of the gravity data begins with converting the gravimeter's counter reading to a relative gravity value using the instrument's conversion table. Then, using the standard Equations A1-A6 in the Appendix. In which, they reduce the relative gravity values of the gravimeter from drift, latitude, and elevation (free-air, Bougeur, and terrain) errors. Next, one absolute base station is used to transform these corrected relative gravity values into absolute gravity. The aim of processing is to correctly and accurately calculate and map each of the gravity and Bougeur anomalies using Equations A5 and A6 in the Appendix (Kearey, 2002; Shahani 1976).

The terrain correction is calculated using the Geosoft Oasis Montaj program and a Digital Terrain Modeling (DTM) of (1"x1" arc-sec). This DTM is available for download directly from the Global Mapper website. Salaee (2015) found that Geosoft software produced reliable results as compared to the manual Hammer method (a method of manually performing terrain correction TC), with the accuracy difference between the two methods ranging from 0.01 to $0.02 \mathrm{mGal}$ (Salaee, 2015; Geosoft manual, 2008).

\section{Results and Discussion}

Before the gravity measurements being used, they were validated. Following that, the absolute gravity and its anomalies will be determined.

\section{Accuracy of the Terrestrial Gravity Survey}

The accuracy of both relative base stations and the surveyed gravity points was checked at the international base station in Rania (a district in the surveyed area) (see Figure 4). However, due to the Iraq-Iran war, this base station has been lost and vanished. Its place, on the other hand, was discovered due to its accessible position. The absolute gravity of the base station was 979,630.25 mGal when measured between 1979 and 1984 (Hussein, 2016). The gravity value of survey differed by a small amount of $0.41 \mathrm{mGal}$ from the actual gravity value of the international base station. 
Volume 6 Issue 24 (December 2021) PP. 213-225

DOI: 10.35631/JISTM.624021

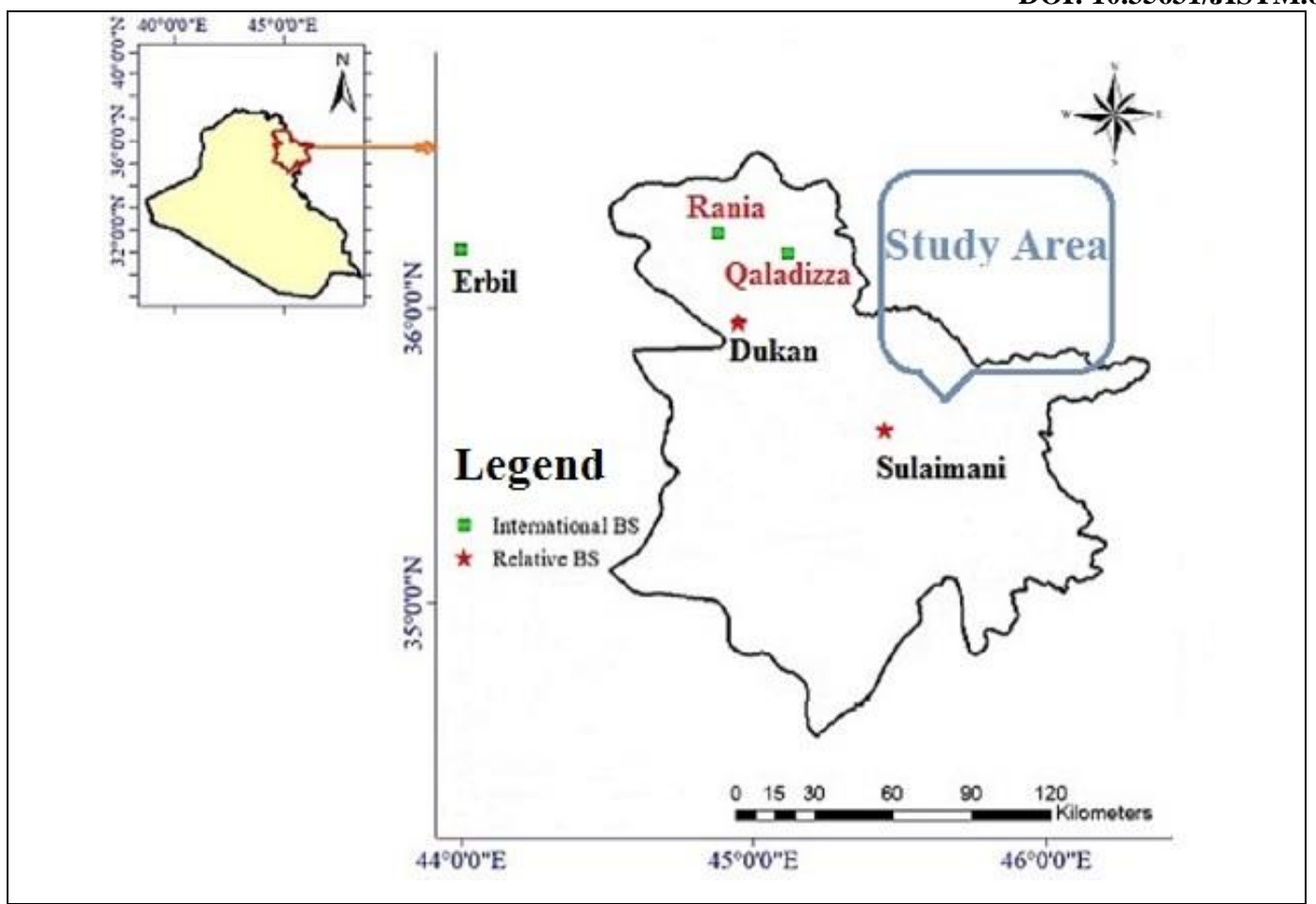

Figure 4: Location of Absolute (International) and Relative Base Stations

N.B.: Rania and Qaladizza international base stations are not exist and they almost lost.

The accuracy of both type of gravity anomaly is determined by the sum of errors from all types of gravity reductions. The accuracy of each stage of measurement and processing, as well as the specifications of both the gravimeter and GPS, and the accuracy of the DTM itself, are all mentioned in Table 2. The error of each reduction can be calculated by taking the derivative of its equation, then using Equation 1 to calculate the accuracy of the gravity anomalies (Salaee, 2015).

$$
E_{\text {total }}=\sqrt{\left(E_{\text {reading }}\right)^{2}+\left(E_{\text {drift }}\right)^{2}+\left(E_{\text {latitude }}\right)^{2}+\left(E_{\text {Free-Air }}\right)^{2}+\left(E_{\text {Bouguer }}\right)^{2}+\left(E_{\text {Terrain }}\right)^{2}}
$$

As a result, the gravimeter's counter reading error $( \pm 0.01 \mathrm{mGal})$, drift $( \pm 0.03 \mathrm{mGal})$, and latitude $( \pm 0.004 \mathrm{mGal})$ corrections decide the precision of gravity anomaly $(\Delta \mathrm{g})$. Therefore, $\Delta \mathrm{g}$ would be accurate to $\pm 0.03 \mathrm{mGal}$. Since the errors of Bouguer and terrain are so minor, they can be overlooked. However, the error of elevation in both DTM and which measured by Garmin handheld lead to raise the Bouguer anomaly (BA) error to $\pm 3.1 \mathrm{mGal}$ as shown in Table 3.

\section{Mapping Of The Gravity Anomalies}

The computed gravity anomalies of the 160 gravity points after the gravity reductions were mapped using Geographic Information System (GIS) via ArcGIS10.5 Software 2020. The distribution of the gravity and Bouguer anomalies in the study area as shown in Figures 5 and 6. The trend of both gravity and Bouguer anomalies illustrates the match with the topography of the terrain as shown in the Shuttle Radar Topographic Mission (SRTM)-with medium 
frequency Digital Elevation Model DEM in Figure 7. It means that the anomalies were inversely related with the elevation of the points. In which the mountainous areas distinguish by low anomaly values and vice versa for the plain areas.

\begin{tabular}{|c|c|c|c|c|c|}
\hline No. & $\begin{array}{l}\text { Type of } \\
\text { error }\end{array}$ & $\begin{array}{c}\text { Dependent } \\
\text { error } \\
(\mathrm{mGal})\end{array}$ & $\begin{array}{c}\text { Error in } \\
\Delta g \\
\text { (mGal) }\end{array}$ & Equation & $\begin{array}{c}\text { Source of } \\
\text { information }\end{array}$ \\
\hline 1 & Reading & $\begin{array}{l}\text { Counter } \\
\text { Reading }\end{array}$ & 0.01 & - & $\begin{array}{c}\text { Gravimeter } \\
\text { Manual }\end{array}$ \\
\hline 2 & Drift & Drift & 0.03 & Standard error & Salaee, 2015 \\
\hline 3 & Latitude & Latitude & $5 \mathrm{~m}$ & - & $\begin{array}{c}\text { GPS } \\
\text { Specifications }\end{array}$ \\
\hline 4 & Free-air & Elevation & $10 \mathrm{~m}$ & $0.3086^{*} \mathrm{eh}$ & $\begin{array}{c}\text { GPS } \\
\text { Specifications }\end{array}$ \\
\hline 5 & Bouguer & $\begin{array}{l}\text { Density } \\
\text { and } \\
\text { elevation }\end{array}$ & $\begin{array}{c}0.1 \mathrm{~g} / \mathrm{cc} \\
10 \mathrm{~m}\end{array}$ & $\begin{array}{c}0.04191 * \mathrm{e} \rho^{*} \\
\mathrm{eh}\end{array}$ & $\begin{array}{c}\text { Ameen, } 2007 \\
\text { Karim, } 2008 \\
\text { Betoshi, } 2010\end{array}$ \\
\hline 6 & Terrain & $\begin{array}{l}\text { Density, } \\
\text { horizontal } \\
\text { and } \\
\text { elevation }\end{array}$ & $\begin{array}{c}0.1 \mathrm{~g} / \mathrm{cc}, \\
5 \mathrm{~m} \text { and } \\
10 \mathrm{~m}\end{array}$ & - & Salaee, 2015 \\
\hline
\end{tabular}

Table 3: Equations and Data Input for Determining the Accuracy of Gravity Anomalies

\begin{tabular}{ccccc}
\hline No. & Type of Error & $\begin{array}{c}\text { Error } \\
(\mathbf{m G a l})\end{array}$ & $\begin{array}{c}\text { Error in } \\
\boldsymbol{\Delta g} \\
(\mathbf{m G a l})\end{array}$ & $\begin{array}{c}\text { Error in } \boldsymbol{B A} \\
(\mathbf{m G a l})\end{array}$ \\
\hline 1 & Reading & 0.01 & 0.01 & 0.01 \\
2 & Drift & 0.03 & 0.03 & 0.03 \\
3 & Latitude & 0.004 & 0.004 & 0.004 \\
4 & Free-Air & 3.1 & - & 3.1 \\
5 & Bouguer & 0.04 & - & 0.04 \\
6 & Terrain & 0.005 & - & 0.005 \\
Accuracy in (mGal) & - & \pm 0.03 & \pm 3.1
\end{tabular}

$\Delta \mathrm{g}=$ Gravity anomaly. $\mathrm{BA}=$ Bouguer anomaly.

${ }^{1}$ The density of crust is calibrated from 2.67 to 2.27 based on density logs of oil wells as presented in the studies of (Betoshi, 2010; Karim, 2008 and Ameen, 2007). 
Volume 6 Issue 24 (December 2021) PP. 213-225 DOI: 10.35631/JISTM.624021

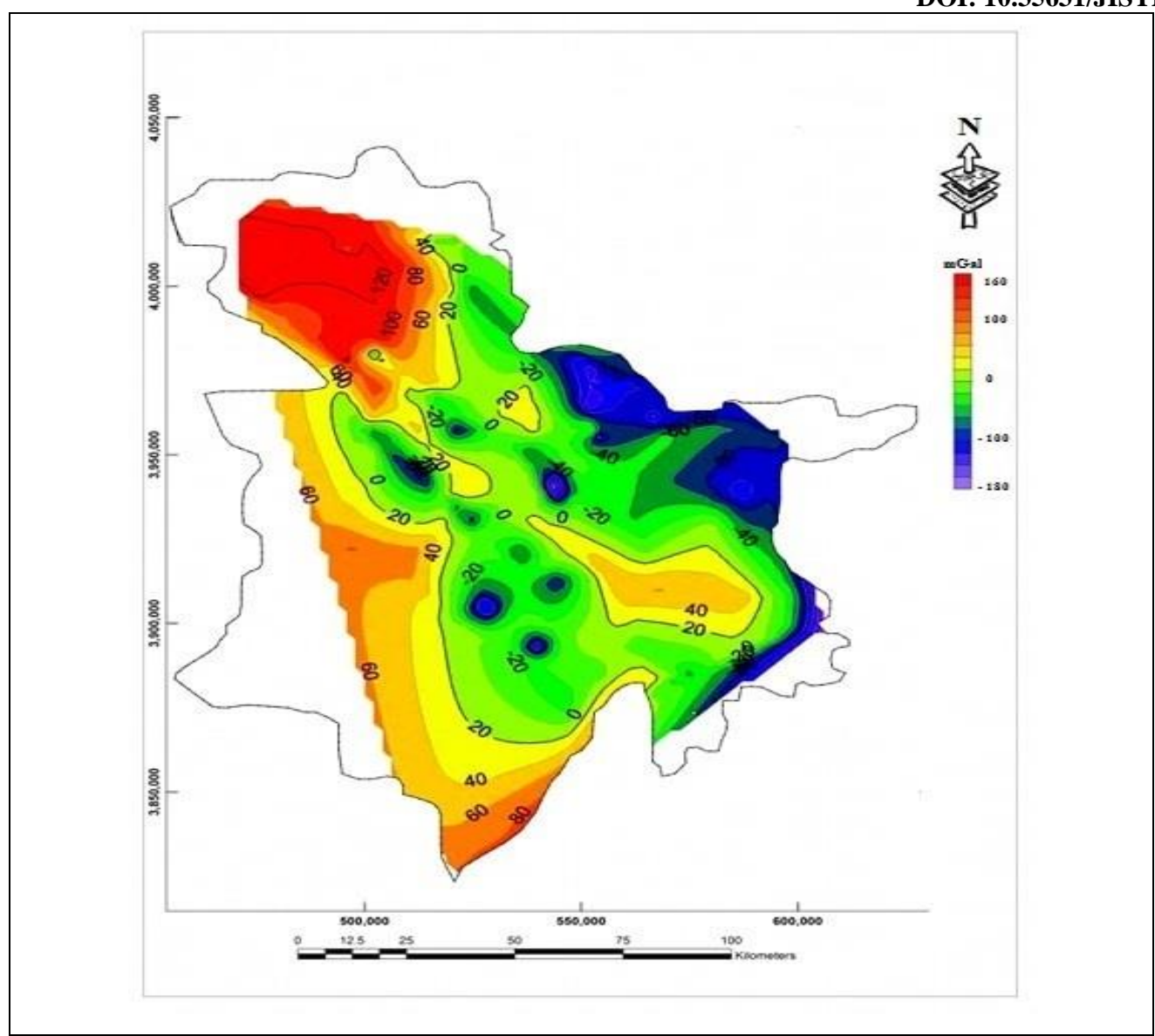

Figure 5: Gravity Anomaly ( $\Delta \mathrm{g})$ from the Terrestrial Survey

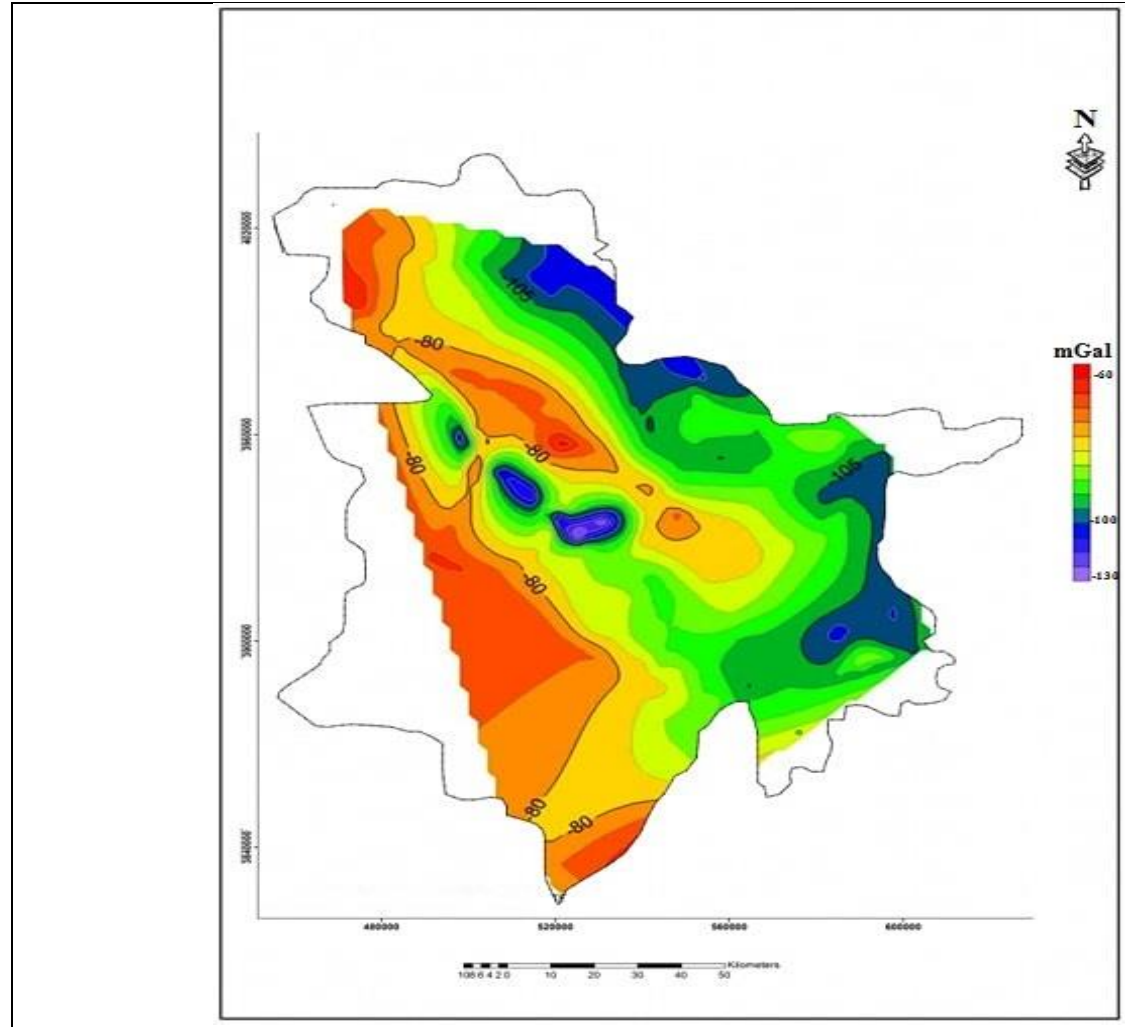




\section{Figure 6: Bouguer Anomaly (BA) from the Terrestrial Survey}

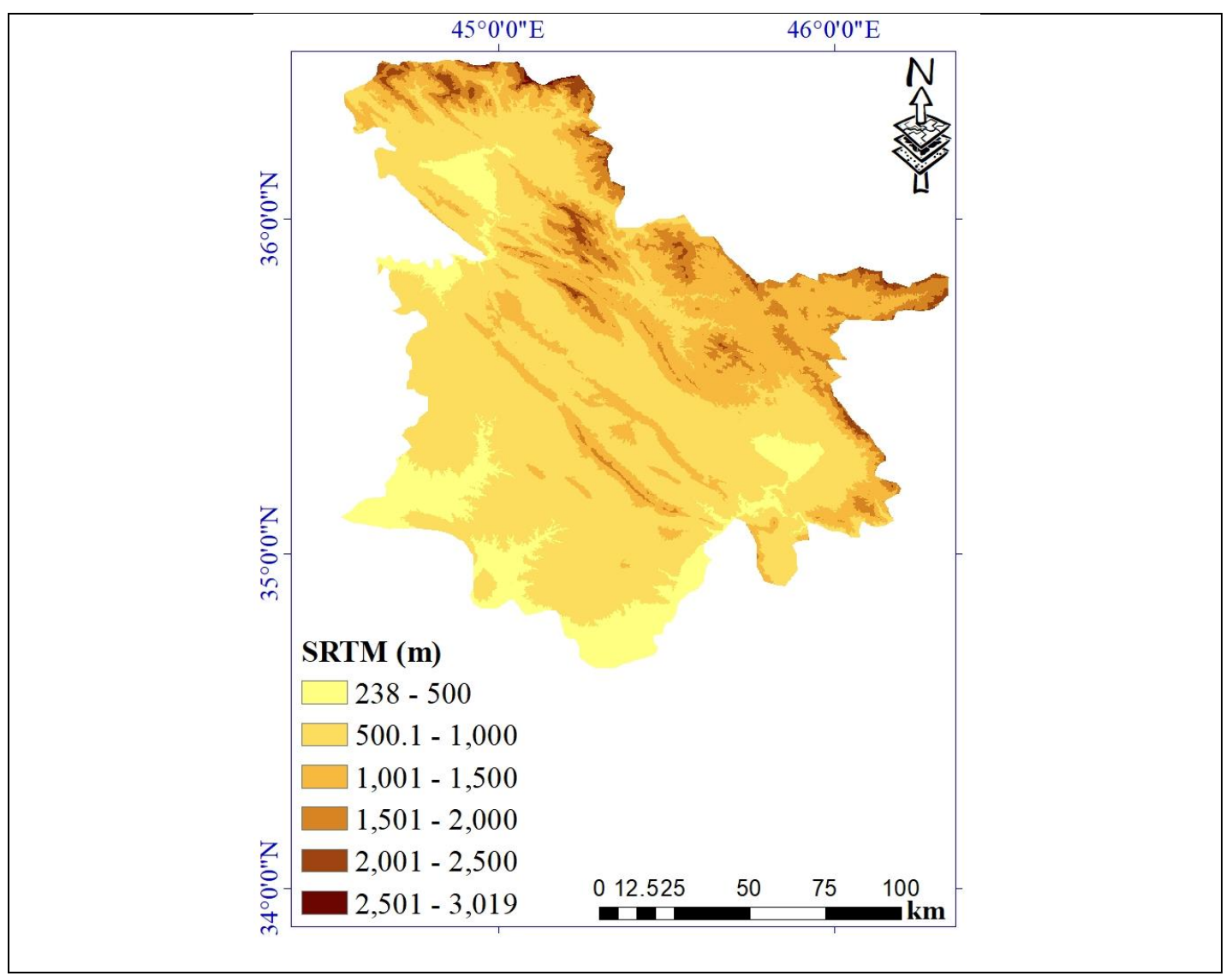

Source: (Jalal et al., 2020)

\section{Figure 7: SRTM DEM of the Study Area}

\section{Conclusions}

A systematic terrestrial gravity survey is conducted for the entire research area in this study. The results show the suitability of the measurements after processing the gravity data and measuring the precision of the gravity values. The accuracy of both $\Delta \mathrm{g}$ and BA was \pm 0.03 $\mathrm{mGal}$ and $\pm 3.1 \mathrm{mGal}$, respectively. After processing and mapping of $\Delta \mathrm{g}$ and BA, the inversely relationship between the gravity anomaly value with the elevation can be seen. As a result, As a result, the mountainous areas along the Iraq-Iran border have the lowest anomaly values.

\section{Acknowledgement}

The authors would like to express their appreciation to his excellency of Sulaymaniyah Governor Dr. Haval Abubakir for providing the helicopter and covering half of the gravity survey field work costs.

\section{References}

Ameen, T. (2007). A Gravity Survey Between Kirkuk and Bazyan and Its Geological Implications; Kurdistan Region, Iraq", M.Sc. Thesis, Department of Geology, College of Science, University of Sulaimani, Iraq. (117 extra gravity points delivered from the author are not presented in the thesis). 
ArcGIS 10.5 Software (2020).

Autodesk Civil 3D Software, 2021.

Betoshi, P. M. A., 2010. The Detailed Gravity and Magnetic Work Study in Sharazoor Area, Kurdistan Region, Iraq", PhD Thesis, Department of Geology, College of Science, University of Sulaimani, Iraq.

BGI (Bureau Gravimetrique International- International Gravimetric Bureau-in English), Email address: bgi@get.omp.eu.

Dobrin M.B. (1960). Introduction to Geophysical Perspecting, McGraw Hill Company, 2nd Ed., USA, 229.

Garmin (2006) Handheld GPS 60cx.

Geosoft Reference Manual (2008). Montaj Gravity \& Terrain Correction. Geosoft Inc. www.geosoft.com).urfer

Heiskanen W. and Meinesz V. (1958). The Earth and Its Gravity Field, McGraw-Hill Book Company, Inc. USA, 33.

Heiskanen W.A. and Mortiz, H. (1967). Physical Geodesy, W. H. Freeman and Company, USA, 48.

Hussein M. (2016) Development a Comprehensive Geodatabase for Iraqi Geodetic Networks, Master Thesis, Building and Construction Department, University of Technology, Baghdad, Iraq.

Instruction manual for LaCoste and Romberg (1970), Inc., Model G Geodetic Gravity Meter, No. 243.

Jalal S., Musa T., Ameen T., Md Din A., Wan Aris W., Ebrahim J. (2020). Optimizing Global Digital Elevation Model (GDEM) and Accuracy of Derived DEM from GPS Points for Iraq's Mountainous Areas, Elsevier, J. Geodesy and Geodynamics, Vol. 11, No. 5, 338349. https://doi.org/10.1016/j.geog.2020.06.004.

Jalal S. J. Musa T.A, Md Din A.H, Wan Aris W., Shen W. and Pa,suya M.F. (2019). Influential Factors on the Accuracy of Local Geoid Modeling, Elsevier, J. Geodesy and Geodynamics, Vol. 10, No. 6, 439-445.

Karim, A. (2008). The Gravity and Magnetic Work Surveys at North East of Chamchamal City- Kurdistan Region, Iraq, M.Sc. Thesis, Department of Geology, College of Science, University of Sulaimani, Iraq.

Kearey P., Brooks M. and Hill I. (2002). An Introduction to Geophysical Exploration, Blackwell Science Ltd, 3rd Ed., Hong Kong, 125-127.

Ministry of Health and Environment (MHE), Department of Mines Affairs (2017). Agreement of the Prohibition on the Use, Store, Produce and Transport of Anti-Individual Mines and the destruction of those mines, Iraq, 43 (in Arabic).

Ministry of Planning, Regional Planning Board (1992). Existing Development of Sulaymaniyah Governorate in 1990, Study No.975, Baghdad, Iraq, 17 (in Arabic).

Parasnis D.S. (1997). Principles of Applied Geophysics, Chapman and Hall, 5th Ed., London, $U K, 64$.

ESA (1999). European Space Agency, Gravity Field and Steady-State Ocean Circulation Mission; Reports for Mission Selection, The Fourth Candidate Earth Explorer Missions, SP-1233, 6-20.

Pinon D. (2016). Development of a Precise Gravimetric Geoid Model for Argentina, M.Sc. Thesis, School of Mathematical and Geospatial Sciences, College of Science Engineering and Health, RMIT University, Australia, 39, 78. 
Salaee, M. A. (2015). Interpretation of the Gravity Survey Data of Kalak- Bardarash Area; Northwest Erbil City- Iraqi Kurdistan Region, M.Sc. Thesis, Department of Geology, College of Science, University of Salahaddin, Iraq.

Shahani P.B. (1976). Advanced Surveying, Oxford and IBH Publishing Co., 2nd Ed., New Delhi, India, 399.

Vaniček P., Kingdon R. and Santos M. (2012). Geoid Versus Quasigeoid: A Case of Physics Versus Geometry, J. Contributions to Geophysics and Geodesy, 42.

\section{Appendix}

$$
\text { Drift Correction }=\left(\mathrm{t}_{\mathrm{obs}}-\mathrm{t}_{\mathrm{base}}\right) \mathrm{x} \text { drift rate }
$$

Where,

$t_{\text {base: }}$ Observed time at the gravity base station.

$t_{\text {obs: }}$ : Observed time at the detailed gravity point.

Where,

$$
\text { Latitude correction: } \mathrm{g}_{\varphi}=\mathrm{g}_{0}\left(1+\mathrm{k}_{1} \sin ^{2} \varphi-\mathrm{k} 2 \sin ^{2} 2 \varphi\right)
$$

$\mathrm{g}_{\varphi}$ : Gravity value at a certain latitude.

$\mathrm{g}_{0}$ : Gravity value at equator $=978,013.8 \mathrm{mGal}$.

$\varphi$ : Observed value of the latitude at the detailed point.

Topographic correction (Free-air Correction): $\mathrm{FAC}=+0.3086 \mathrm{H} \quad$ (in $\mathrm{mGal}$ )

Where:

$\mathrm{H}$ : The height of the station above the datum (in meter).

Topographic correction (Bouguer correction): $\mathrm{BC}=+0.04191 \rho$ h (in $\mathrm{mGal}$ )

Where,

$\mathrm{H}$ : The height of the station above the datum (in meter).

$\rho$ : Density of crust (from the point to the sea level or geoid) of earth $=2.67 \mathrm{~g} / \mathrm{cc}$.

Gravity anomalies can be divided into three categories: gravity anomaly (g), Bouguer anomaly (BA), and free-air anomaly.

$$
\begin{gathered}
\Delta \mathrm{g}=\mathrm{g}_{\text {obs }}-\mathrm{g}_{\varphi} \\
\mathrm{BA}=\Delta \mathrm{g}-\mathrm{BC}+\mathrm{FAC}+\mathrm{TC}
\end{gathered}
$$

Where:

$\mathrm{g}_{\mathrm{obs}}$ : Absolute gravity value of the observed point.

$\Delta \mathrm{g}$ : Gravity anomaly.

$\mathrm{g}_{\varphi}$ : Gravity value at a certain latitude.

FAA: Free-air anomaly.

BC: Bouguer correction.

BA: Bouguer anomaly.

TC: Terrain correction. 